\title{
The Future of Maintenance of Certification: A Reaction to the Paper by Kevin B. Weiss, MD
}

Paul V. Miles, MD

American health care is in the middle of a second revolution in quality. The Flexner revolution that occurred almost 100 years ago led to profound changes in physician training. The current revolution is addressing quality of care. Specialty board certification and maintenance of certification are key drivers of physician professional development and improvement of care.

I am honored to be able to participate in this anniversary celebration and to be invited to respond to Dr. Weiss' comments about the future of maintenance of certification (MOC). ${ }^{1} \mathrm{My}$ wife Anne and I have been part of the American Board of Family Medicine family for more than 10 years-more than a quarter of its existence-and we value the close friendships that have we have made.

Dr. Weiss has presented an excellent history of specialty board certification and MOC. He has made a compelling argument for additional changes to the MOC process to meet the board's missions of assuring the public of physician quality, including increased patient and public involvement, increased transparency, addressing variation in diagnostic decision making, increased focus on system-based practice and physician accountability. I would like address 2 of the issues he has raised. The first is the role of the public in MOC and the second is physician accountability.

Paul Batalden at Dartmouth has developed an equation for quality that states: quality $=$ science + context. ${ }^{2}$ Patients are entitled to the best science in medicine, but that is not enough to assure the

From the American Board of Pediatrics, Chapel Hill, North Carolina.

Funding: An honorarium from the American Board of Family Medicine was received for this presentation.

Conflict of interest: none declared.

Prior presentation: Presentation given at the American Board of Family Medicine 40th Anniversary, Lexington, Kentucky, 24 October 2009.

Corresponding author: Paul Miles, MD, FAAP, Senior Vice President for Quality and Maintenance of Certification, American Board of Pediatrics, 111 Silver Cedar Court, Chapel Hill, NC 27514 (E-mail: pvm@abpeds.org). highest quality. The scientific and technical care must be delivered within the context of what patients want and need, and they have to be active partners in determining this. If we are to improve quality we must improve the science we practice, but we must also better understand how to influence the contextual issues that influence our patients' health. MOC is trying to capture some of this by requiring assessment of physicians' communication skills and professionalism, but we can go further.

Rather than the profession independently defining the standards for communication, professionalism, and patient-centered care, we should invite patients to help us do this. We should continually ask patients what they want from health care and do our best to meet their needs. For example, do they really want to choose between good care and bad care or do they want good care no matter where they go? The answer to this question influences the choice of 2 very different approaches to the use of measurement data. All of the 6 core physician competencies except medical knowledge require either feedback or collaboration from patients to assess and improve quality of care. Similarly, except for a relatively few examples involving clinical effectiveness, all 6 of the Institute of Medicine dimensions of quality require involvement of the patient and/or the multidisciplinary team to define, assess, and improve care.

Even if physicians wanted to, they cannot regulate their own profession without involving patients, the public, and other health care team members. Boards can set some of the standards but for many other standards patient and public input is essential. A good example is unprofessional conduct, which often involves legal issues and behavior that can only be evaluated at a local level in the local context. Although the boards have the responsibility to set standards for physician professional development, patients should have a major say relative to the competencies of communication, professionalism, patient care, and system-based prac- 
tice. They should also have a major say in defining quality dimensions of timeliness, efficiency (waits and delays), patient-centered care, and efficacy.

In the 2000 millennium issue of Lancet, the Spanish historian Lázaro ${ }^{3}$ stated that one of most profound changes in medicine during the past 1000 years has been the recent development of informed consent. He argued that this has changed the interaction between physicians and patients from a vertical to a horizontal relationship, with the patient in control. Previously, the physician was the holder of knowledge and dispenser of advice that was not to be challenged; now, the physician is a consultant who is invited into the life of the patient to provide care, offer advice, and help the patient make informed decisions. It is time for the profession to partner with patients at the national level, not just the individual patient level. This means more public members involved in the MOC process and more partnerships with patients and public entities to develop standards and tools for assessing physician competencies.

The second part of Batalden's quality equation relates to the need for improving science in medicine. Although the external world is focused on access and cost of care, the revolution occurring within the profession is centered around how to promote professional development to deliver optimum quality of care outcomes and how to master the tremendous explosion of new knowledge and complex technology. Outcome-based medicine has been made possible by the ability to define, measure, and improve quality of care. ${ }^{4-7}$ Historically, physicians have said to patients, "Trust me, I am a physician." Clinicians have acted in good faith that they were delivering the best possible quality of care to their patients. Only recently have patients and the public begun to reply, "We trust you, but show us the data."

Physicians who have traditionally practiced anecdotally, relying on their individual perceptions of quality and outcomes based on a relatively small number of patients in their individual practices, are now asked to formally assess and improve outcomes of care. The focus on individual patients has led to significant progress, but health services researchers have discovered that it has also resulted in significant practice variation, often with undesired outcomes. Faced with evidence of variation in care, physicians are now beginning to ask themselves "Is this data real?"
"If it is, how do I respond?" "How do I really know that what I do works?" "How can I improve?" There are external factors driving physicians to change practice behavior, including measurement and regulation, financial penalties and incentives, and the threat of malpractice. Increasingly, however, physicians are realizing that if they are risking a patient's life on the care they and their team deliver, they have the professional obligation to actually measure whether the care they deliver is safe, timely, and evidencebased, whether it meets patients' needs, and, if there are gaps in quality, to improve the quality of care. ${ }^{7}$

To be meaningful and relevant, the MOC process must help physicians achieve this. Although the use of science to generate new knowledge remains critical, perhaps the most important recent advancement has been the introduction of improvement science into health care. Quality improvement science has provided a method for systematically analyzing and improving processes of care that can lead to improved outcomes. In addition, the focus on quality, especially related to patient safety, has introduced a systems approach to addressing quality and safety. MOC requires that physicians be competent in system-based practice, including teamwork and patient safety. ${ }^{8-10}$

Finally, the requirement that all diplomates measure and improve quality of care requires an approach to assessment and standard setting that is different than the assessment of medical knowledge. Several health services researchers ${ }^{11,12}$ have pointed out the inherent difficulties in trying to distinguish whether one individual physician's clinical performance differs from another in a valid, statistically significant manner. Issues of small sample size, how much of a patient's care can be attributed to any one individual physician, and how to adjust for confounding factors such as severity of illness makes measuring individual physician clinical quality a difficult task. In addition, the greater problem of clinical quality in American health care is not that a few physicians and hospitals provide low-quality care, but rather that there is a significant gap between the mean performance of the majority of providers and optimum care. This approach represents a shift from searching for a small number of low-performing "bad apples" to a focus on improving the performance of the majority of physicians, the "good apples" (Figure 1). 
Figure 1. Comparison of minimum standards to quality improvement approach to improving physician quality. A: Looking for "bad apples" by sanctioning performance that fails to meet minimal standards. B: Improving "good apples" by focusing change on the entire distribution.

Looking for Bad Apples

(Sanctioning performance that fails to meet minimal standards)

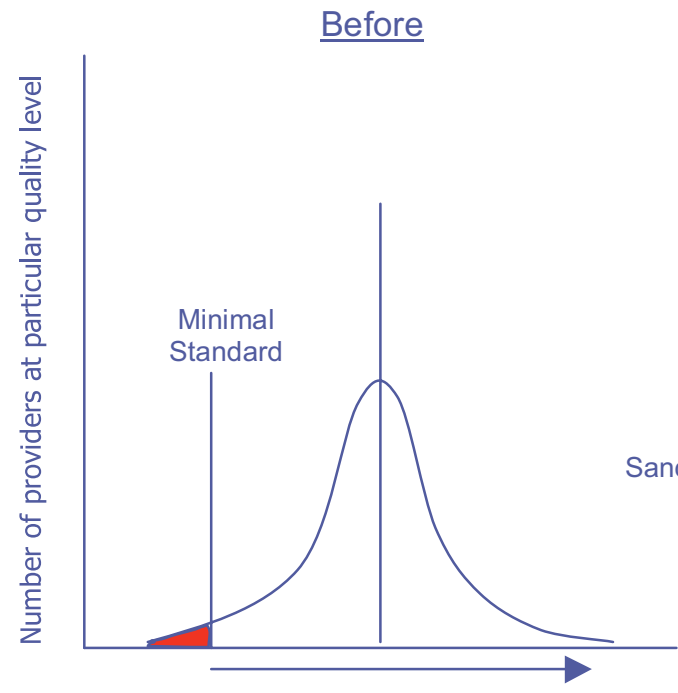

Higher Quality

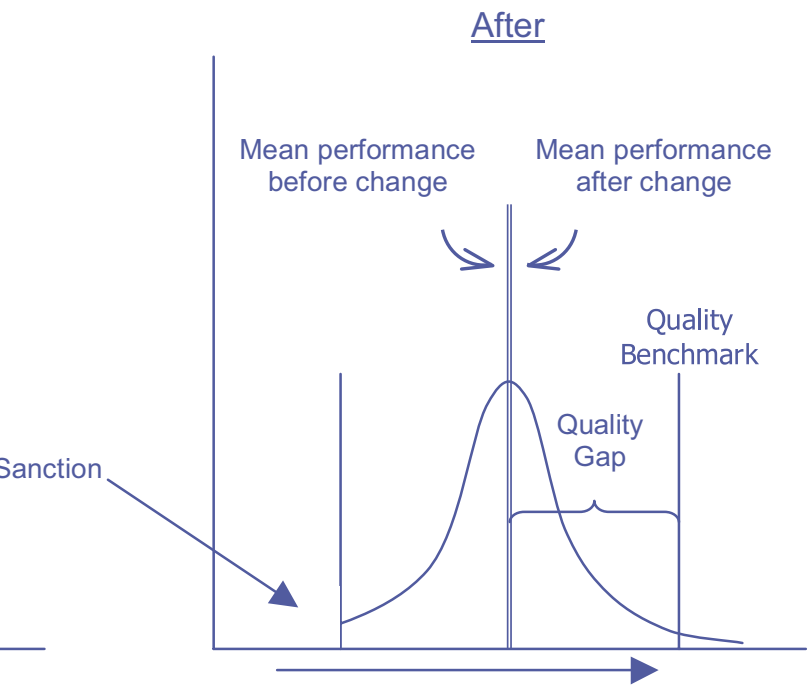

Higher Quality

Improving Good Apples

(Focusing change on the entire distribution)

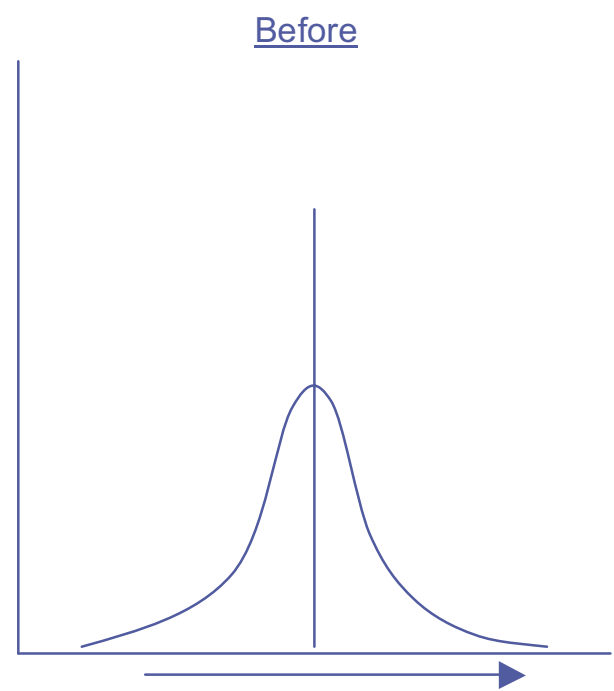

Higher Quality

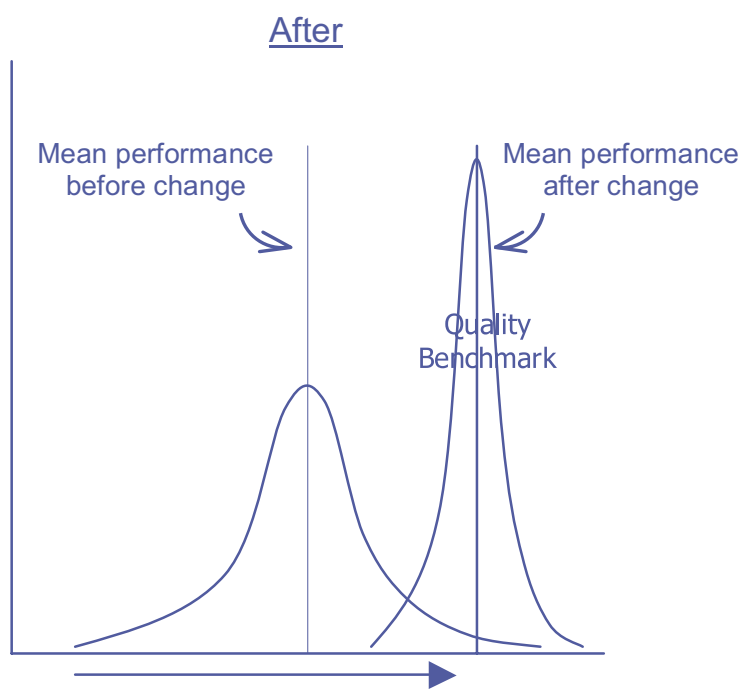

Higher Quality
The challenge is how to help all physicians and their care teams deliver better care no matter where they are rather than trying to change only a few low-performing physicians. Because board certification is a voluntary process it relies on physician professionalism to work- the inherent desire to do what is right for patients. The boards have fundamentally altered their roles from simply assessing physicians to assessing and helping physicians improve their own professional development and performance in practice. In doing this, the American Board of Medical Specialties boards have become drivers for changing physician practice behavior to improve quality of care.

The following bulleted items suggest how MOC for family physicians might look in the future: 
- outcome driven (part 2 and 4 activities that help diplomates assess and demonstrate improvement in care);

- population based (MOC requirement to improve care for a defined population of patients);

- interdisciplinary (requirement to demonstrate competency in teamwork and systems analysis and redesign);

- focused on patients with special health care needs (demonstrated competency in chronic care and attributes of a medical home);

- electronic and technology based (real-time data shared with patients, care teams, and colleagues and an electronic health record that directly supports MOC activities and processes);

- part of a larger system responsible for the health of a defined population with representative patient and public members involved in MOC (MOC requirement to be competent in analyzing ${ }^{9}$ and helping to fix system issues that affect quality of care);

- collaborative practice (regional and national);

- predictive and longitudinal care (genetics); and

- outcome-based education (maintain a portfolio that demonstrates lifelong professional development and includes data documenting professional development over time).

\section{References}

1. Weiss KB. Future of board certification in a new era of public accountability. J Am Board Fam Med 2010; 23(Suppl):S32-9.

2. Nelson EC, Batalden PB, Lazar JS. Practice-based learning and improvement: a clinical improvement action guide. 2nd Ed. Oakbrook Terrace, IL: Joint Commission Resources; 2007. p. 6.

3. Lázaro J. Doctors' status: changes in the past millennium. Lancet 1999;354(Suppl 4):SIV 17.

4. Institute of Medicine. Crossing the quality chasm: a new health system for the 21st century. Washington, D.C.: National Academies Press; 2001.

5. Wennberg JE. Understanding geographic variations in health care delivery. N Engl J Med 1999;340: 52-3.

6. Brook RH, Park RE, Chassin MR, Solomon DH, Keesey J, Kosecoff J. Predicting the appropriate use of carotid endarterectomy, upper gastrointestinal endoscopy, and coronary angiography. N Engl J Med 1990;323:1173-7.

7. McGlynn EA, Asch SM, Adams J, et al. The quality of health care delivered to adults in the United States. N Engl J Med 2003;348:2635-45.

8. Brennan TA. Physicians' professional responsibility to improve the quality of care. Acad Med 2002;77: 973-80.

9. Horowitz SD, Miller SH, Miles PV. Board certification and physician quality. Med Educ 2004;38: $10-1$.

10. Landon BE, Normand SL, Blumenthal D, Daley J. Physician clinical performance assessment: prospects and barriers. JAMA 2003;290:1183-9.

11. Greenfield S, Kaplan SH, Kahn R, Ninomiya J, Griffith JL. Profiling care provided by different groups of physicians: effects of patient case-mix (bias) and physician-level clustering on quality assessment results. Ann Intern Med 2002;136:111-21.

12. Audet AM, Doty MM, Shamasdin J, Schoenbaum S. Measure, learn, and improve: Have physicians begun to engage in the quality improvement cycle? Health Aff 2005;24:843-53. 